Presented at the International Workshop on ECR Ion Sources, Grenoble, France, September 14-16. 1988

High Performance Single Stage Operation of the LBL ECR and the Design of an Advanced ECR Ion Source

C.M. Lyneis

September 1988

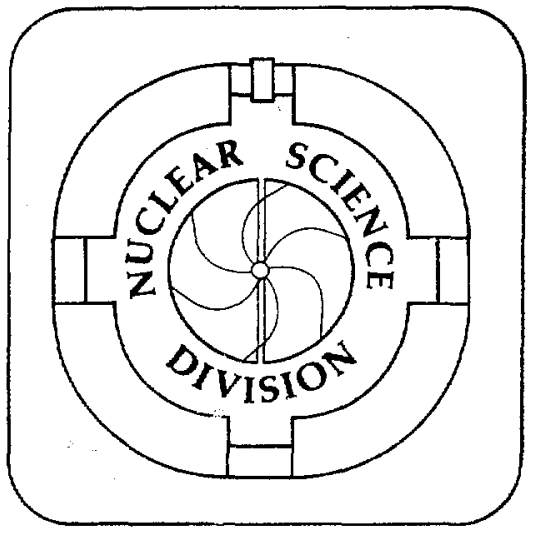

Prepared four the U.S, Department of Energy under Cantract Number DE-AC03-76SI00098. 


\title{
High Performance Single Stage Operation of the LBL ECR and the Design of an Advanced ECR Ion Source*
}

\author{
C.M. Lyneis \\ Nuclear Science Division \\ Lawrence Berkeley Laboratory \\ 1 Cyclotron Road \\ Berkeley, California 94720
}

\section{DISCLAIMER}

\begin{abstract}
This report was prepared as an account of work sponsored by an agency of the Unitod States Government. Neither the United States Government nor any agency thereof, nor any of their employoes, makes any warranty, express or implied, or astisnes any legal liability or responsibility for the accuracy, compteteness, or usefulness of any information, apparatus, product, or process disclosed, or represents that its use would not infringe privately ownod rights. Reference herein to any specifie commercial product, process, or service by trade name, trademark, manufacturer, of otherwise does not necessarily constitute or imply its endarsement, recom. mendation, or favoring by the United States Government or any agency thercof. The views and opinions of authors expressed herein do not necessarily state or reflect thowe of the United States Government or any agency thereof.
\end{abstract}

*This work was supported by the Director, Office of Energy Research, Office of High Energy and Nuclear Physics, Nuclear Physics Division of the U.S. Department of Energy under Contract DE AC03-76SF00098. 
IHGH PERFORMANCE SINGLE STAGE OPERATION OF THE LBL ECR AND THE DESIGN OF AN ADVANCED ECR ION SOURCE*

\author{
C.M. LYNEIS \\ Nuclear Science Division \\ Lawrence Berkeley Laboratory \\ I Cyclotron Road \\ Berkeley, California 94720
}

\begin{abstract}
A new mode of operation using only the second stage of the LBL ECR has been developed. This single stage mode produces charge states and currents equal to or better than the traditional two stage operation of the LBL ECR for a variety of gases such as nitrogen, oxygen, and argon. The critical pararneter for this mode appears to be conditioning the plasma chamber walls with a coating of $\mathrm{SiO}_{2}$. Various models to explain this effect will be discussed along with implications for ECR ion source design. A new Advanced ECR ion source which will operate at $14 \mathrm{GHz}$ is being designed for the 88-Inch Cyclotron. Construction is scheduled to begin in the fall of 1988 and test operation should begin in the fall of 1989. The design includes hollow core copper wire solenoids, iron yoke, a $\mathrm{Nd}-\mathrm{Fe}-\mathrm{B}$ sextupole, radial pumping, and access to the plasma chamber.
\end{abstract}

\title{
$\underline{1 \text { - INTRODUCTION }}$
}

The LBL ECR source has been in regular operation with the 88-Inch Cyclotron for almost 4 years. It has proved to be both a reliable and flexible ion source capable of a wide range of ion beams./1/ The development this year of a high temperature oven, which can operate up to $2000^{\circ} \mathrm{C}$, greatly increased the variety of ions available The new oven is described in another paper in the conference.(D.J. Clark and C.M. Lyneis) Recently, a new operating mode using only the second stage of the LBL ECR source was discovered, which produced more intense high charge state currents than had previously be produced with both stages. As described below, this operating mode requires a coating of $\mathrm{SiO}_{2}$ on the plasma chamber walls.

The AECR (Advanced ECR ion source) is being designed for use with the 88-Inch Cyclotron. The AECR which will operate at $14.5 \mathrm{GHz}$ is expected to provide significantly enhanced performance in terms of the intensity and maximum charge states for heavy-jon beams compared to the present LBL ECR which operates at $6.4 \mathrm{GHz}$. This expeftationtis " $16 \mathrm{GHz}$./2/. The AECR w wl cptplement rather than replace the LBL ECR. This will allow access time for ECR ion source development, while always having one ECR source available for the cyclotron. In addition, two sources will allow more flexible scheduling of beams from the cyclotron since we will be able to change sources after 
running a solid that causes short term poisoning of the source. The design of the AECR source will be discussed in the second part of this paper.

\section{2 - SILICON AND SINGLE STAGE OPERATION}

The day to day performance of the LBL ECR ion source is strongly influenced by the conditions of its walls. In particular, the addition of $\mathrm{SiO}_{2}$ coating to the walls significantly enhances its performance for high charge state ions such as $\mathrm{N}^{6+}, \mathrm{O}^{7+}$, and $\mathrm{Ar}^{14+}, / 3 /$ The long lifetime of the coating effects (up to several months) and the requirement for a variety of ECR produced beams for the 88-Inch Cyclotron have precluded a systematic study of this effect. However we now have more than 3 years of data on the source performance which clearly demonstrates the basic effect of coating the walls with $\mathrm{SiO}_{2}$. Most surprising was the discovery that under certain conditions the LBL ECR could produce more intense high charge state currents operating without the first stage than has ever been done operating it as two stage source. This single stage operating mode offers the possibility of building high performance single stage ECR ion sources without the added cost and complexity associated with a first stage.

The maximum $\mathrm{O}^{7+}$ current is a convenient measure of the LBL ECR's performance level and a good predictor of how well the source will produce other high charge state ions. The source is often run with oxygen either as a beam for the cyclotron or as a mixing gas for heavier ions. As a result we have frequent measurements of its oxygen performance In Fig. 1, the $\mathrm{O}^{7+}$ current produced by the LBL ECR is plotted versus time. From day to day or week to week there is considerable scatter in the data reflecting a variety of factors such as source tuning, contamination of the walls, and use of metal beams. However after SiH4 was run on Feb. 26 1986, the initial good performance was followed by a gradual decline in the time averaged performance. The cause of the gradual decline appears to be the slow erosion of $\mathrm{SiO}_{2}$ from the surface of the chamber walls by the ECR plasma. A small amount of silicon was added in March 1987, but the decline continued until late in July when the source was run for several days with a mixture of $\mathrm{SiH}_{4}$ and $\mathrm{O}_{2}$ to produce $\mathrm{Si}^{6+}$. Following this the $\mathrm{O}^{7+}$ currents increased from $5 \mathrm{e} \mu \mathrm{A}$ to $15 \mathrm{e} \mu \mathrm{A}$. Since that time the use of silicon has been more frequent as dictated by the experimental program on the cyclotron.

During late December 1987 and January 1988, silicon was frequently run. It was during this period that we found it was not only possible to operated with the first stage off, it actually produced better results. This came as a surprise since previous work at LBL /4/ and at many other ECR sources had always shown two stage operation enhanced the high charge state performance. $/ 5,6 /$ In order to verify that this was true one stage performance without any parasitic ECR zone in the first stage, a plug was installed blocking the opening between first and second state at the location labeled as point $A$ in Fig. 2. A test in this configuration made a few hours after the end of a 4 day silicon nun produced $20 \mathrm{e} \mu \mathrm{A}$ of $\mathrm{O}^{7+}, 116 \mathrm{e} \mu \mathrm{A}$ of $\mathrm{O}^{6+}$ and $133 \mathrm{e} \mu \mathrm{A}$ of $\mathrm{O}^{5+}$. Also during this time period $32 \mathrm{e} \mu \mathrm{A}$ of $\mathrm{N}^{6+}$ and $110 \mathrm{e} \mu \mathrm{A}$ of $\mathrm{N}^{5+}$ and $1.6 \mathrm{e} \mu \mathrm{A}$ of $\mathrm{Ar}^{14+}$ were produced in single stage operation. All of these were measured at $10 \mathrm{kV}$ extraction voltage and 
represent record performance levels for the LBL ECR. The axial magnet field profile used in the single state tests is also shown in Fig.2. An iron plug has been added in the first stage to allow sufficient magnetic field strength so a $10.36 \mathrm{CHz}$ klystron could be used in the first stage.

The relationship between the silicon coating and the effect of the first stage on source performance is strengthened by the following observations. Just after a heavy coating of $\mathrm{SiO}_{2}$ the best source performance is obtained with the first stage shut off. After a few weeks of operation the best performance is obtained by running the first stage at low RF power. As more time passes the first stage power needs to be increased. Finally after a few months even with maximum first stage output the source performance continues to decrease. During this period some improvement in $\mathrm{O}^{7+}$ can be obtained by adding helium.

The enhanced performance in single stage operation after coating the walls with $\mathrm{SiO}_{2}$ appears to result from an increase in the production of cold electrons at the wall of the plasma chamber. As pointed out previously $/ 3 /$ the coefficient for secondary emission for electron impact on $\mathrm{SiO}_{2}$ is between 2 and 4 considerably above 1.3 for bare copper. Geller et al $/ 7 /$ found that coating the walls of Ferromafios with good electron donor materials with low work functions resulted in improved performance. In equilibrium the production of cold electrons in the plasma must equal the losses. In the second stage of an ECR source, cold electrons are injected from the first stage, produced by electron impact ionization of neutral atoms and ions, and produced by secondary emission at the walls. The losses of cold electrons come from loss of confinement, recombination, and ECR heating. The optimum plasma density in an ECR source seems to be set by stability requirements related to the critical density. $I /$ If the walls serve as a sufficient source of cold electrons to achieve the optimum plasma density, then it is no longer necessary to supply cold electrons from the first stage.

Although with an $\mathrm{SiO}_{2}$ coating the LBL ECR works extremely well as a one stage source, there are practical advantages to being abje to operate it as a two stage source. First, in single stage mode the source tuning is rather narrow and the neutral pressure in the second stage must be very precisely controlled. Second, it is not always convenient to renew the $\mathrm{SiO}_{2}$ surface by running $\mathrm{SiH}_{4}$ and $\mathrm{O}_{2}$. Third, when the source is used to produce beams from solids the $\mathrm{SiO}_{2}$ coating may get covered over and lose effect. Finally, it is not clear that this effect works equally well for all ECR sources. A test with $\mathrm{SiH}_{4}$ and $\mathrm{O}_{2}$ in the MSU RT-ECR produced a negative result (private communication, $\mathrm{T}$. Antaya). On the other hand, it is strongly beneficial to the LBL ECR and clearly reduces the need for a high perfomance first stage.

\section{3 - THE ADVANCED ECR}

The project to build the AECR and couple it to the cyclotron is scheduled to begin in the fall of 1988 and be completed in 2 years. Phase I of the project will consist of the construction of the AECR driven by single $14 \mathrm{GHz} 2.5 \mathrm{~kW}$ klystron along with the beam analysis system. During Plase II, a second klystron will be purchased to independently 
drive the first stage, an oven to produce beams from solid feeds will be built, and the beam transport system coupling the AECR to the cyclotron will be completed.

The design of the AECR Phase $I$ is illustrated in Fig. 3 and the source parameters are listed in Table 1. The axial magnetic field is produced by three groups of hollow core copper coils and an iron yoke. Each coil group will consist of 12 double layer pancakes with 20 turns per layer. The coils will be wound with $6.5 \mathrm{~mm}$ square hollow core copper wire and be vacuum impregnated with epoxy. Each set of 4 pancakes will be powered by a separate 33 Volt 300 Amp power supply. Because the nine magnet power supplies will each be adjustable it will be possible to vary the axial magnetic field easily. The iron plates between coils 2 and 3 serve to increase the mirror ratio. In Fig. 3, the axial magnetic field is plotted assuming 250 Amps in all coils. This field profile is similar to that used with the LBL ECR as shown in Fig. 2, which was optimized experimentally. The first stage will operate on the "uphill" gradient of the axial magnetic field as is the case in the LBL ECR. The detailed design of transition between first and second stage is not yet complete and this part of the Fig. 3 is only schematic. Optimization of this part of the design is expected to require considerable experimentation. During the first year both stages will be driven by a single $14.5 \mathrm{GHz} 2.5 \mathrm{~kW}$ klystron. The choice of $14.5 \mathrm{GHz}$ was made because commercial klystron amplifier systems are available at this frequency. Even though it may not be optimal to divide the power between first and second stage, by coating the wall with $\mathrm{SiO}_{2}$ we expect it to produce excellent results for gases such as $\mathrm{N}_{2}$, $\mathrm{O}_{2}$, and $\mathrm{Ar}$ in single stage operation.

The sextupole field is produced by a Nd-Fe-B multipole shown in Fig. 4. This design is optimized to give sufficient field at the wall and still allow for radial pumping, access for ovens, and the direct insertion of refractory materials for the production of beams from solids. The easy axis of the permanent magnet pieces are plus and minus $36^{\circ}$ from the radial direction as shown in Fig. 4 . With this configuration, the plasma flutes will strike the wall directly adjacent to the cooling tube bored in the copper sextupole structure. The design of the sextupole is complicated by the requirement for radial access, but this access makes the design and use of ovens easier. The magnitude of the sextupole field at the wali between adjacent pieces is $0.72 \mathrm{~T}$ and $0.60 \mathrm{~T}$ in the gaps. It appears that unless higher strength permanent magnets become available, stronger sextupole fields required at frequencies much above $14 \mathrm{GHz}$ can be obtained only with closed permanent magnet structures or with superconducting coils. Pumping for the second stage and extraction stage will be provided by $240 \mathrm{l} / \mathrm{s}$ turbomolecular pumps.

\section{4 - BEYOND THE AECR}

The last decade has seen a real improvement in heavy-ion accelerator performance as a result of the development of ECR sources. As the operating frequency of ECR sources is increased to improve their performance, the construction costs become higher and the technology more difficult. However, even at $28 \mathrm{GHz}$ the costs are small compared to a typical accelerator facility. With this in mind, we have begun work on the conceptual design for a $28 \mathrm{GHz}$ ECR source. 
At present, the effor is focussed on calculating the magnetic fields, current densities, and forces for the coil configurations necessiry to produce the solenoid and sextupole fields. We are evaluating the trade offs involved in choosing the size of the plasma chamber. To minimize the microwave power required, it would be advantageous to use al small plasma chanber (about $70 \mathrm{~mm}$ diameter). This is important since the scaling of power density with frequency is not clear and high power densities may be needed. On the other hand, making the superconducting magnet structure small becomes difficult beciuse the current densities increase as mugnet size decreases. Also the space needed for heat shields in the cryostat and a water cooled chamber wall place a limit on how small it can be made.

The preliminary design assumes separate solenoid and sextupole coils wound with $\mathrm{Nb}-\mathrm{Ti}$ wire, an iron return yoke to minimize the effects of stray magnetic field, a $28 \mathrm{GHz} 20 \mathrm{~kW}$ "laboratory scale" gyrotron, $/ 8 /$ and a plasma volume as small as is consistent with the constraints discussed above.

\section{ACKNOWLEDGMENT}

Many members of the ECR conmunity have given their advice and help on aspects to the design of the AECR including A. Drentje, F. Meyer, T. Antaya, R. Pardo, and Y. Jongen. D.J. Clark designed the beam transport system between the AECR and the cyclotron. For the conceptual design of the $28 \mathrm{GHz}$ ECR source, P. Countryman is analyzing the magnetic fields and forces and $\mathrm{R}$. Wolgast is designing the cryostat. We have benefitted greatly from discussions with the MSU group lead by T. Antuya, who are designing the SC-ECR.

\section{REFERENCES}

11/ Lyneis, C.M., Proc. 11th Int. Conf. on Cyclotrons and their Applications (1987) 707.

2/ Geller,R., Jacquot,B., and Sortais, P., Nucl. Instr. and Meth. A243 (1986) 244.

13) Lyneis, C.M., Proc. Int. Conf. on ECR Ion Sources and their Applications, MSUCP-47, (1987) 42.

14/ Lyneis, C.M. and Clark, D.J., IEEE Trans. on Nucl. Sci. NS-32 (1985) 1745.

15/ Geller, R., IEEE Trans. on Nucl. Sci., NS-23 (1976) 904.

16/ Antaya, T.A., Xie, Z.Q., Contributed Papers of the 7th Workshop on ECR Ion Sources, Jül-Conf-57 (1986) 73.

7/ Geller,R., Bourg, F., Briand, P., Debernardi, J., Delaunay, M., Jacquot, B., Ludwig, P., Pauthenet, R, Pontonnier, M., and Sortais, P.,Proc. Int. Conf. on ECR Ion Sources and their Applications, MSUCP-47, (1987) 1.

18/ Craig,L.J., Felch,K., Gold,S., Ives,L., Jongewaard,E., Jory, H., Pirkle, D.,Proc. Int. Conf. on ECR Ion Sources and their Applications, MSUCP-47, (1987) 131

*This work was supported by the Director, Office of Energy Research, Office oi High Energy and Nuclear Physics, Nuclear Physics Division of the U.S. Department of Energy under Contract DE AC03-76SF00098. 
Table 1 - AECR Ion Source Parameters

Magnetic Field

Peak on Axis (T)

At Extraction ( $T$ )

Solenoid Current (A)

Mirror Ratio

Sextupole Material

Sextupole Field at Chamber (T)

Source Dimensions

Solenoid Inner Diameter

Solenoid Outer Diameter

Numier of turn per coil group

Sextupole Inner Diameter

Sextupole Length

Vacuum Chamber Diameter

Plasma Electrode Hole Diameter

Puller Hole Diameter

Gap

RF System

Frequency

Maximum Power

Plasma Chamber and Extraction Pumps

Turbomolecular Pumps
Typical

.82

.64

250

1.57

Nd-Fe-B

.60

.72

.98

.77

300

-.
Maximum

$\mathrm{mm}$

203.

483.

480 .

80.

300

70.

8.0

12.0

10-35

$14.5 \mathrm{GHz}$

$2.5 \mathrm{~kW}$

$240 \mathrm{l} / \mathrm{s}$ 
Performance of the LBL ECR versus time

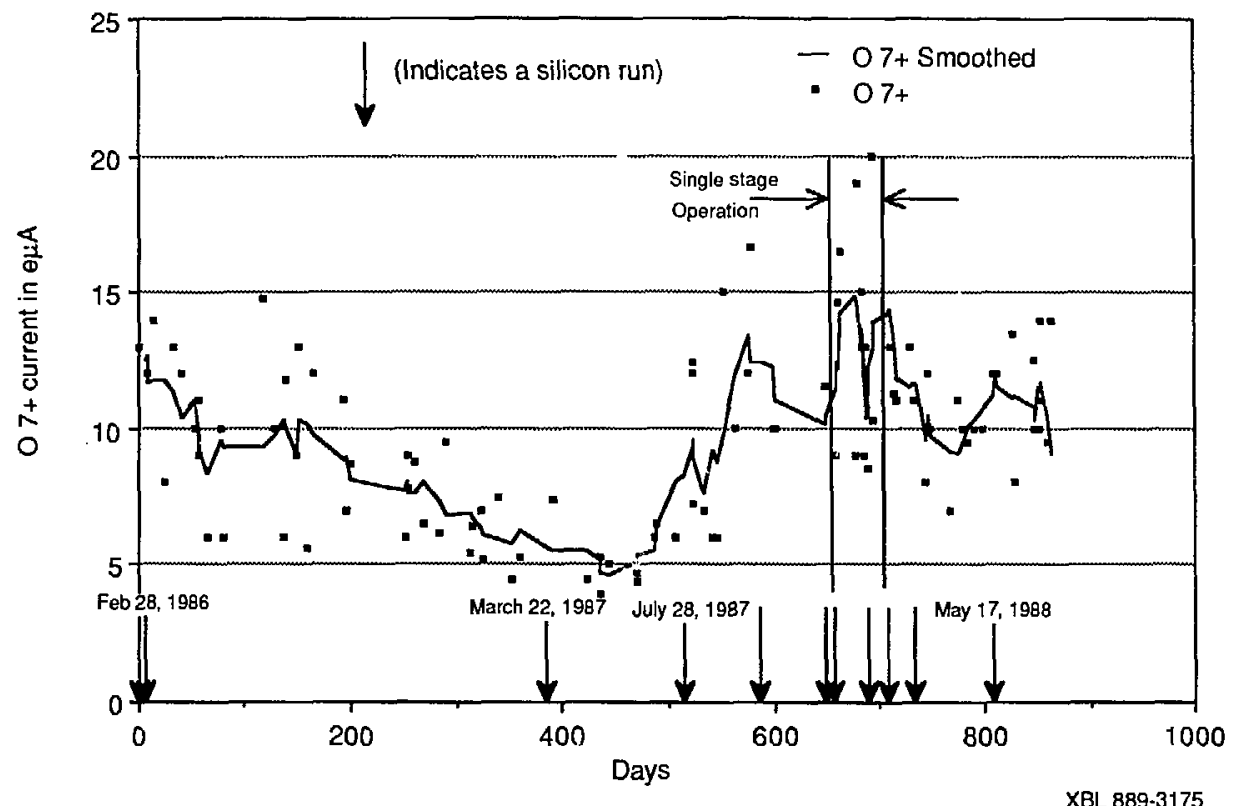

Fig. 1 - The $\mathrm{O}^{7+}$ performance of the LBL ECR is ploted versus time. The slow decline in average performance from February 1986 to March 1987 coincides with a period during which silicon was not nun. In December 1987 and January 1988 heavy usage of silicon made it possible to produce up to $20 \mathrm{e \mu A}$ of $\mathrm{O}^{7+}$ with single stage operation. 


\section{LBL ECR - 1988}

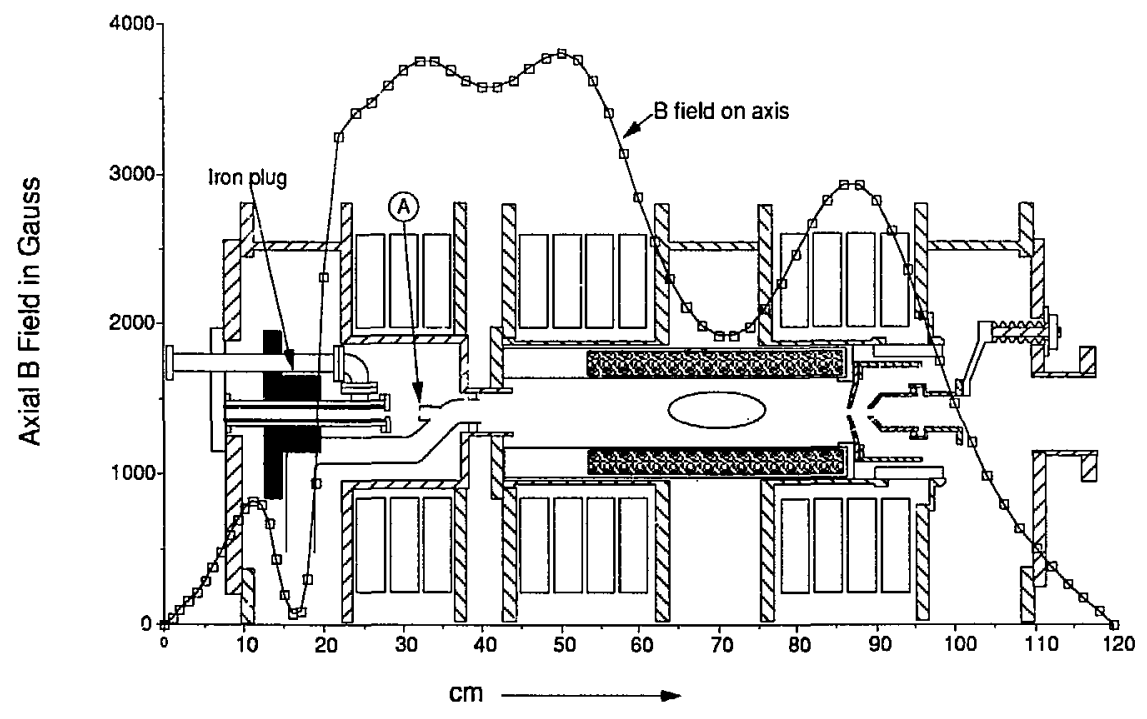

XBL-889-3176

Fig. 2 - Elevation view of the LBL ECR. The axial magnttic field used for single stage operation is indicated by the open squares. To verify true single stage operation the opening at point A was blocked and gas was fed directly into the second stage. 


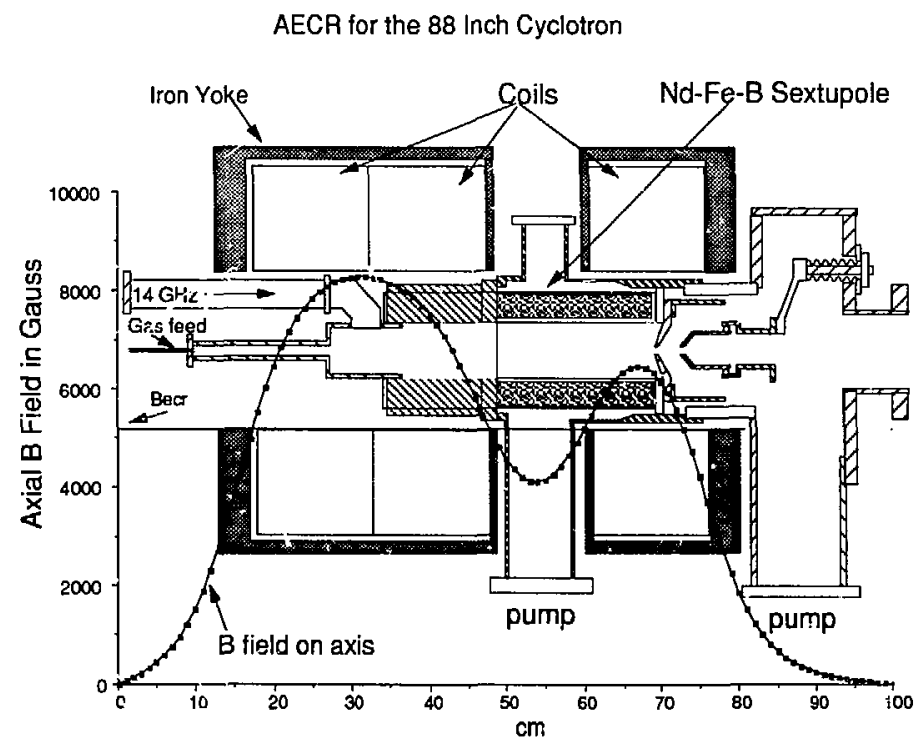

XBL 889-3177

Fig. 3 - Elevation view of the AECR source. The axial magnetic field corresponding to 250 amp current in the coils is superimposed on the draving. 


\section{Nd-Fe-B Sextupole for the AECR}

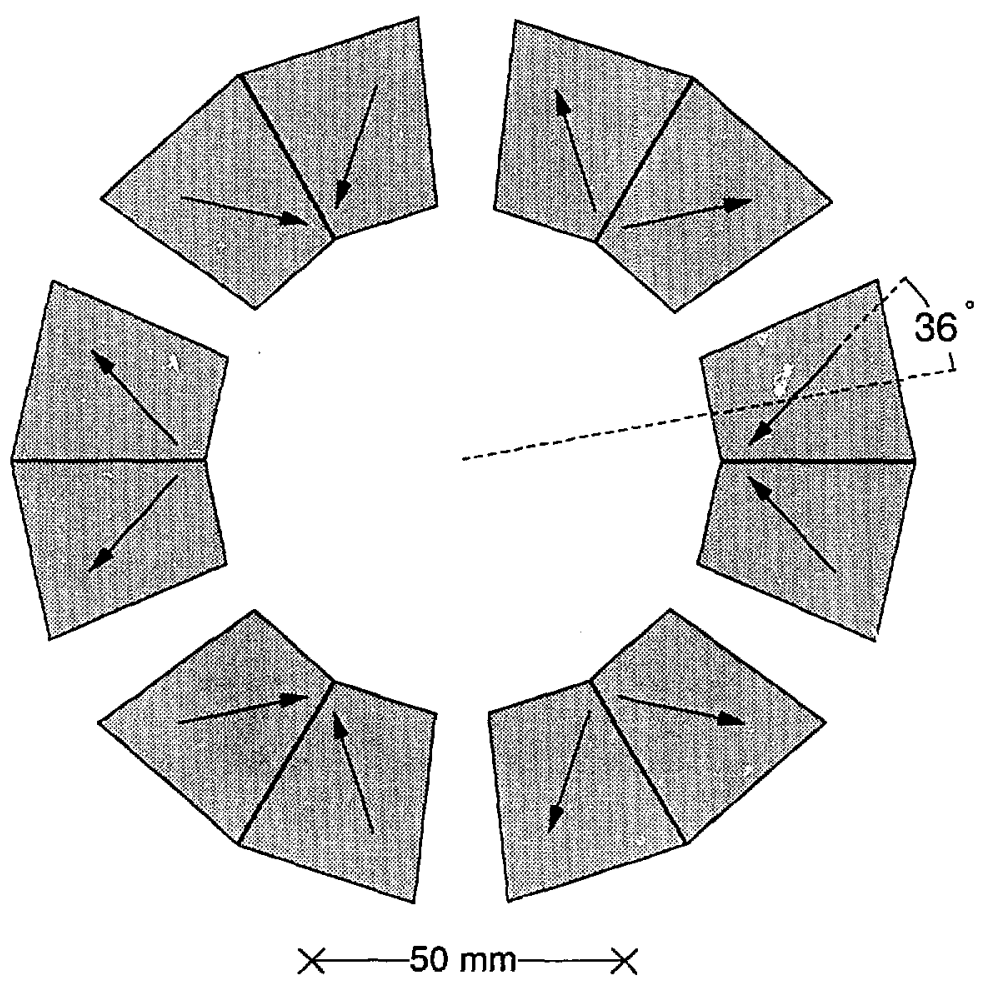

XBL $889-3178$

Fig. 4 - Schematic drawing showing the arrangement of Nd-Fe-B piece making up the sextupole for the AECR. The arrows indicate the magnetization along the easy axis of the permanent magnets. The gaps betwe : : she segments allow for radial pumping and access for an oyen. 